\title{
Two-dimensional transesophageal echocardiography for aortic annular sizing in patients undergoing transcatheter aortic valve implantation
}

\author{
Mohammad A. Sherif ${ }^{1 *}$, Hüseyin Ince', Octavian Maniuc², Therese Reiter ${ }^{2}$, Wolfram Voelker², Georg Ertl'
} and Alper Öner'

\begin{abstract}
Background: Accurate preoperative assessment of the aortic annulus dimension is crucial for successful transcatheter aortic valve implantation (TAVI). In this study we examined the accuracy of a novel method using two-dimensional transesophageal echocardiography (2D-TEE) for measurement of the aortic annulus.

Methods: We evaluated the theoretical impact of the measurement of the annulus diameter and area using the circumcircle of a triangle method on the decision to perform the procedure and choice of the prosthesis size.

Results: Sixty-three consecutive patients were scheduled for TAVI. Mean age was $82 \pm 4$ years, and 25 patients (55.6\%) were female. Mean aortic annulus diameter was $20.3 \pm 2.2 \mathrm{~mm}$ assessed by TEE on the mid-esophageal long-axis view and $23.9 \pm 2.3 \mathrm{~mm}$ using $C T(p<0.001)$. There was a tendency for the TEE derived areas using the new method to be higher $(p<0.001)$. The TEE measurements were on average $42.33 \mathrm{~mm}^{2}$ higher than the CT measurements without an evidence of a systematic over- or under-sizing $(p=1.00)$. Agreement between TEE and CT chosen valve sizes was good overall (kappa $=0.67$ and weighted kappa $=0.71$ ). For patients who turned out to have no AR, the two methods agreed in $84.6 \%$ of patients.
\end{abstract}

Conclusions: $C T$ remanis the gold standard in sizing of the aortic valve annulus. Nevertheless, sizing of the aortic valve annulus using TEE derived area may be helpful. The impact of integration of this method in the algorithm of aortic annulus sizing on the outcome of patients undergoing TAVI should be examined in future studies.

Keywords: TAVI, Sizing, Echocardiography

\section{Background}

Accurate preoperative assessment of the aortic annulus dimension is crucial for successful transcatheter aortic valve implantation (TAVI). Two-dimensional transesophageal echocardiography (2D-TEE) may underestimates the annulus [1]. For this reason, alternative sizing methods based on multidetector computed tomography (CT) [2] und Three-dimensional (3D) TEE [3] have been developed.

CT has become the "gold standard" for non-invasive preoperative evaluation of the aortic root and aortic annulus

\footnotetext{
* Correspondence: mohammad_sherif@hotmail.com

${ }^{1}$ Internal Medicine Centre, Cardiology Department, Rostock University Clinic,

Ernst-Hyedemann- Street 6, 18057 Rostock, Germany

Full list of author information is available at the end of the article
}

prior to TAVI using the balloon expandable EdwardsSapien (ES) bioprosthesis (Edwards Sapien/Sapien XT, Edwards Lifesciences, Irvine, California) [4-6].

However, the proper identification and alignment of the plane on which the virtual ring is situated might be difficult because of heavy calcifications or extremely oval annuli. Both of these issues could lead to distortion of the aortic root. In these cases, patients would benefit most from multimodality imaging [1].

In this study we examined the accuracy of a new method using 2D-TEE for non-invasive preoperative evaluation of the aortic annulus prior to TAVI using the balloon expandable ES bioprosthesis. 


\section{Methods}

\section{Study design and patients}

The new method to measure the aortic valve annulus was applied in 63 consecutive patients with severe symptomatic tricuspid aortic stenosis (aortic valve area [AVA] $<1 \mathrm{~cm}^{2}$ or indexed AVA $<0.6 \mathrm{~cm}^{2} / \mathrm{m}^{2}$ ) were recruited and underwent successful TAVI using the balloon expandable EdwardsSapien (ES) bioprosthesis (Edwards Sapien/Sapien XT, Edwards Lifesciences, Irvine, California through the transfemoral route.

Accordingly, a theoretical decision was made for the size of the valve to be implanted; the virtual valve. The echocardiographers were blinded regarding the name of the patients and the measurements of the CT. These patients have undergone TAVI; nevertheless, the annulus measurement used for the procedure was done using CT as a standard in our institution. Manual reconstructions were performed with clinical software (Siemens Syngo Dynamics VIA; Siemens Healthcare, Erlangen, Germany) in a standard fashion [7]. Briefly, using the 3D multiplanar reformation (MPR) tool, the analysis plane was shifted and rotated to intersect the 3 lowest insertion points of the aortic valve leaflets. At this level, planimetry of the annulus lumen was performed. Accordingly, the area of the annulus and the mean diameter were calculated. The valve size was chosen according to the valve-sizing chart recommended from the manufacturer.

TAVI was done using the balloon expandable ES bioprosthesis. Post-operatively, the presence, degree and type (paravalvular versus transvalvular) of aortic regurgitation (AR) were recorded in all patients using TTE and aortography and quantified according to the VARC criteria [8].

Because of the nature of the study, an ethical approval was not required for this study.

\section{Echocardiographic assessment}

A comprehensive TTE and TEE was performed preoperatively. The severity of aortic stenosis was assessed by the transvalvular mean gradient and aortic valve area (AVA), which was calculated with the continuity equation and planimetry [9].

\section{Circumcircle of a triangle method}

Annular size measurement was performed using the enlarged view of the mid-esophageal short axis (approximately $30^{\circ}$ to $50^{\circ}$ ) during the early systolic phase of the cardiac cycle. The short-axis views of the aortic valve were generated at the insertion of the cusps in systole. The mid-esophageal AV short axis view was obtained from the mid-esophageal window by advancing or withdrawing the probe until the AV comes into view and then turning the probe to center the AV in the display. The image depth was adjusted to between 10 to $12 \mathrm{~cm}$ to position the $\mathrm{AV}$ in the middle of the display. Next, the multiplane angle was rotated forward to approximately 30 to $60^{\circ}$ until a symmetrical image of all three cusps of the aortic valve and the coronary sinuses comes into view. This view shows how the leaflets join together along trifoliate zones of apposition extending from peripheral attachments at the sinutubular junction to the centroid of the valvular orifice (Fig. 1). These zones of apposition are the true commissures. The aortal end of the commissures correlates anatomically to the upper end of the inter-leaflet triangle and at the same time they represent the sinutubular junction (blue ring in Fig. 2). Three points were defined (red circles Fig. 1). Three lines were drawn between these points and the resulting triangle was used to identify the circle that intersects the three vertices of the triangle i.e. circumcircle of the triangle (yellow circle in Fig. 3).

The area and the radius of this circle were calculated und accordingly the size of the valve was chosen.

Knowing the length $(\mathrm{a}, \mathrm{b}, \mathrm{c})$ of the three sides of the triangle (Fig. 3), the radius of its circumcircle was calculated.

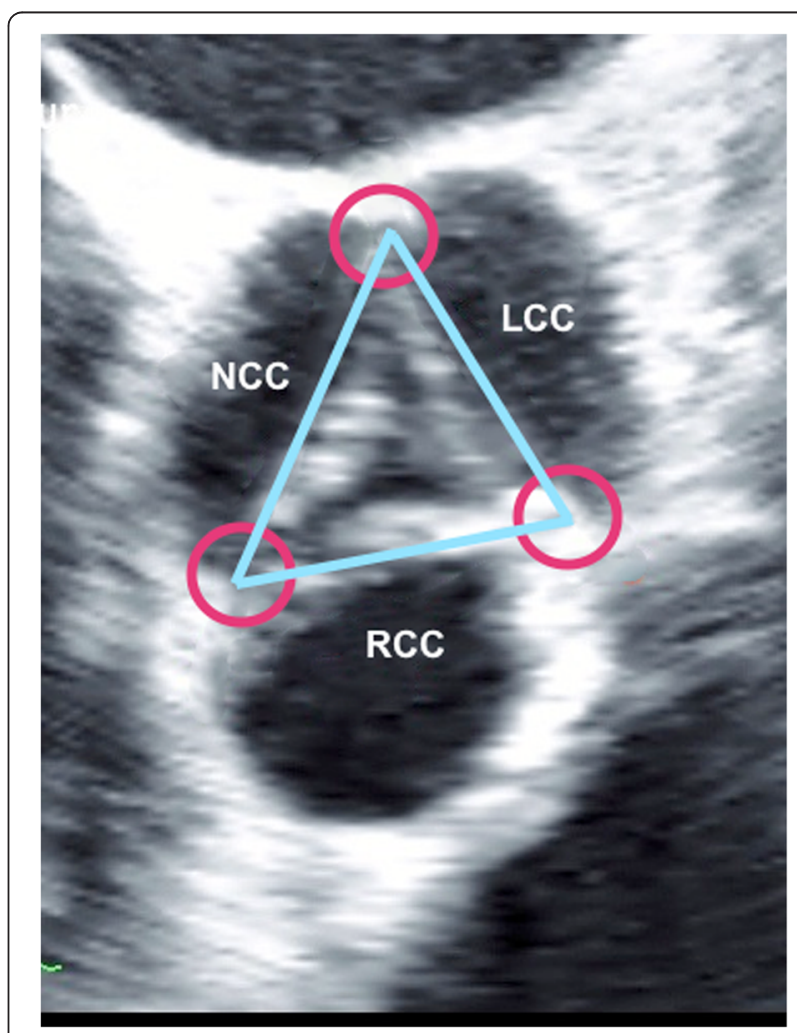

Fig. 1 Annular size measurement using the enlarged view of the mid-oesophageal short axis (approximately $30^{\circ}$ to $50^{\circ}$ ). The short-axis views of the aortic valve are generated at the insertion of the cusps in early systole. Red circles identify the thickened parts at the sites of peripheral attachment of the zones of apposition between the aortic valve leaflets. They represent also the vertices of the interleaflet triangles. LCC: left coronary cusp, RCC: right coronary cusp, NCC: non-coronary cusp 


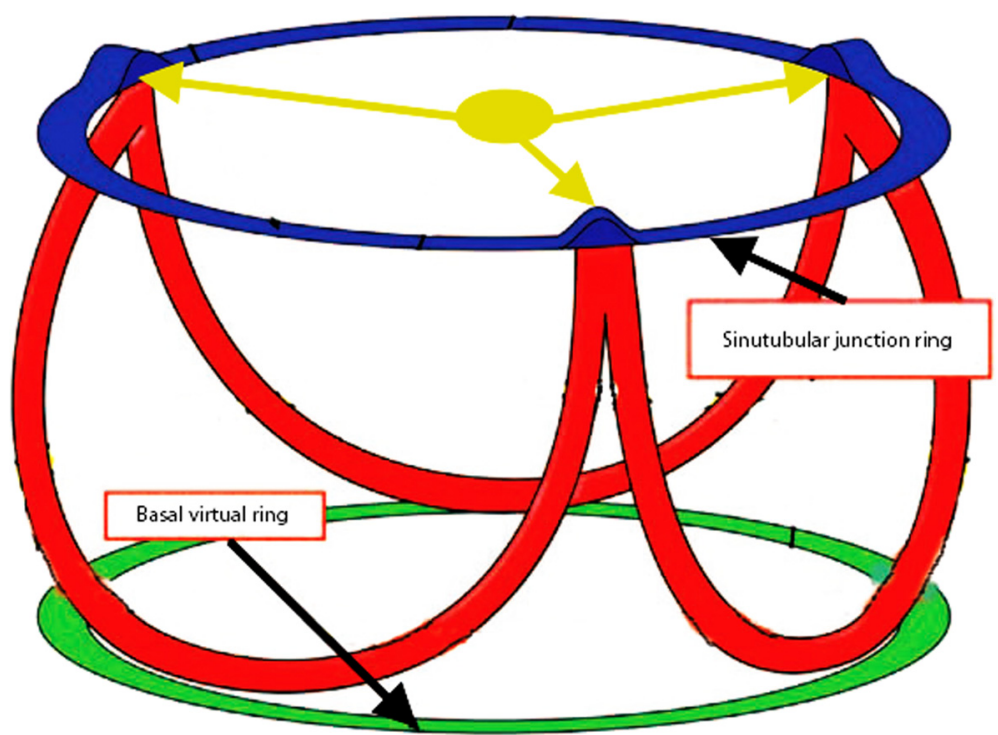

Fig. 2 Schematic drawing describes the anatomic arrangement of the aortic valve leaflets supported in crown-like fashion. The diameter at the level of the basal attachment of the leaflets (green ring) is the one used for sizing using CT. The top of the crown, namely the sinutubular junction is the level used to measure the annulus in the study (blue ring)

\section{Statistical analysis}

Statistical analysis was done using Minitab software (Minitab, Release 13.1, State College, Pennsylvania). Data were expressed as mean $\pm \mathrm{SD}$ or percent. Comparisons of measurements and valve sizes according to the methodology were performed using the $t$-test or chisquare test as appropriate.

The Bland-Altman analysis was done to see whether there is any bias between the different methods of sizing, i.e. whether the mean values for the methods differ. Two

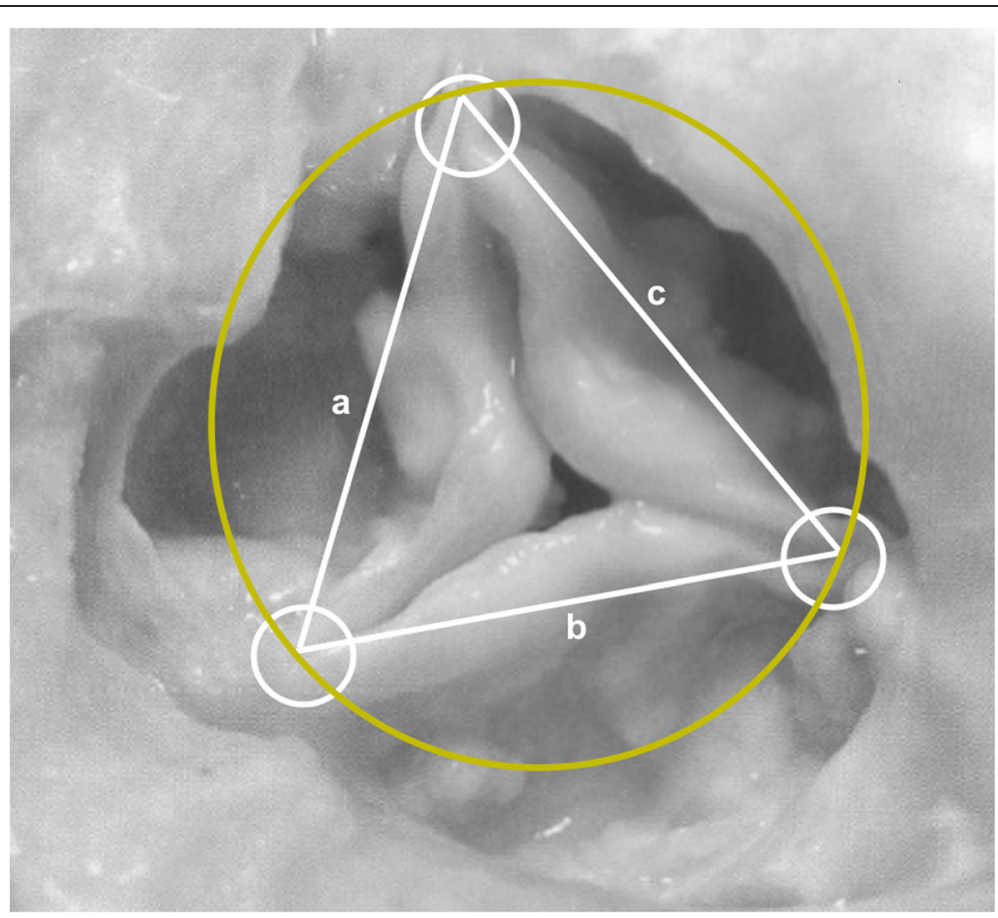

Fig. 3 Schematic drawing describes the circumcircle of a triangle method. Three points are defined (white circles). Three lines are drawn between these points $(a, b, c)$ and the resulting triangle issued to identify the circle (yellow circle) that intersects the three vertices of the triangle 
standard measures of agreement between the valve sizes for each method were also done: kappa and weighted kappa. As a rough guide, values of kappa less than or equal to 0.2 suggest poor agreement, values between 0.2 and 0.40 suggest fair agreement, values between 0.4 and 0.6 suggest moderate agreement, values between 0.6 and 0.8 suggest good agreement and values between 0.8 and 1.0 suggest very good agreement. The difference between kappa and weighted kappa, is that weighted kappa takes into account that a valve size of 23 by CT and 29 by TEE suggests worse agreement than, a sizing of 23 by $\mathrm{CT}$ and 26 by TEE. The supporting data are available if required.

\section{Results}

Sixty-three consecutive patients were scheduled for TAVI received TTE, TEE, and CT in our hospital. Mean age was $82 \pm 4$ years, and 35 patients $(55.6 \%)$ were female. Atrial fibrillation was present in 32 patients $(50.8 \%)$. All patients had an anatomical tricuspid aortic valve. Mean aortic valve area was $0.74 \pm 0.31 \mathrm{~cm}^{2}$, and mean gradient was $47.5 \pm 14.6 \mathrm{mmHg}$.

Mean aortic annulus diameter was $20.3 \pm 2.2 \mathrm{~mm}$ assessed by TEE on the mid-esophageal long-axis view and $23.9 \pm 2.3 \mathrm{~mm}$ using CT $(p<0.001)$ (Table 1$)$.

\section{Theoretical impact of the method of measurement of the} annulus on the procedure

We evaluated the theoretical impact of the measurement of the annulus diameter and area assessed by TEE on the decision to perform the procedure and choice of the prosthesis size.

We hypothesized the sizing using $\mathrm{CT}$ as the 'gold standard' and compared the choice of the ES valve based on it to the choice based on TEE.

\section{Comparing valve selection by $\mathrm{CT}$ and TEE derived area}

A Comparison of areas as estimated using CT and TEE and the difference between them is shown in Figs. 4 and 5. There was a tendency for the TEE derived areas to be higher $(p<0.001, t$-test). Interestingly, the mean difference was only $28.5 \mathrm{~mm}^{2}$ for patients who subsequently had no AR and was $64.8 \mathrm{~mm}^{2}$ for patients who had AR grade 1 or 2 , but this difference was not statistically significant ( $p=0.075$, two-sample $t$-test).

The Bland-Altman analysis showed that TEE measurements are on average $42.33 \mathrm{~mm}^{2}$ higher than the CT measurements and that this difference is statistically significant $(p<0.001)$.

The Bland-Altman plot of the difference (TEE derived area minus CT derived area) against the mean area by TEE and CT is shown in Fig. 6. The red dotted lines show the range of differences between the measurements for most (about $95 \%$ ) of individuals.
Table 1 Clinical, echocardiographic and procedural characteristics of the study population

\begin{tabular}{|c|c|}
\hline Variable & Mean \pm SD \\
\hline Age, years & $82.4 \pm 5.5$ \\
\hline Female gender, $\%$ & 55.6 \\
\hline Atrial fibrillation, \% & 50.8 \\
\hline Ejection fraction, \% & $55 \pm 10$ \\
\hline Aortic valve area, $\mathrm{cm}^{2}$ & $0.74 \pm 0.31$ \\
\hline Peak pressure gradient, mmHg & $72.6 \pm 21.4$ \\
\hline Mean pressure gradient, mmHg & $47.5 \pm 14.6$ \\
\hline $\begin{array}{l}\text { Annulus diameter using TEE hinge-to-hinge } \\
\text { (long axis view), mm }\end{array}$ & $20.3 \pm 2.2$ \\
\hline Annulus diameter using $C T, \mathrm{~mm}$ & $23.9 \pm 2.3$ \\
\hline $\begin{array}{l}\text { Annulus diameter according to circumcircle } \\
\text { of a triangle method, } \mathrm{mm}\end{array}$ & $25.6 \pm 2.4$ \\
\hline Annulus area using $C T, \mathrm{~mm}^{2}$ & $453.3 \pm 77.7$ \\
\hline $\begin{array}{l}\text { Annulus area according to circumcircle of a } \\
\text { triangle method, } \mathrm{mm}^{2}\end{array}$ & $495.6 \pm 95.7$ \\
\hline \multicolumn{2}{|l|}{ Access site } \\
\hline Femoral & $65 \%$ \\
\hline Apical & $35 \%$ \\
\hline \multicolumn{2}{|l|}{ Valve size } \\
\hline 23-mm & $36.5 \%$ \\
\hline 26-mm & $47.6 \%$ \\
\hline 29-mm & $15.9 \%$ \\
\hline \multicolumn{2}{|l|}{ Post-operative AR (angiographic) } \\
\hline No & $62 \%$ \\
\hline Minimal/mild & $30 \%$ \\
\hline Moderate & $8 \%$ \\
\hline \multicolumn{2}{|l|}{ Post-operative AR (echocardiographic) } \\
\hline No & $51 \%$ \\
\hline Minimal/mild & $38 \%$ \\
\hline Moderate & $11 \%$ \\
\hline Post-operative peak gradient, mmHg & $20.6 \pm 6.5$ \\
\hline Post-operative mean gradient, mmHg & $11.8 \pm 3.8$ \\
\hline
\end{tabular}

Figure 7 shows the frequencies of the virtual valve sizes according to TEE derived area in comparison to the real valve sizes. We see that the same sizing was made in 50 out of the 63 patients (79.5\%); valve sizes using TEE were higher for 6 patients $(9.5 \%)$ and lower for 7 patients (11\%). There does not seem to be much evidence of a systematic over- or under-sizing $(p=1.00)$. Agreement between TEE and CT chosen valve sizes overall was good $(\mathrm{kappa}=0.67$ and weighted $\mathrm{kappa}=0.71)$.

For patients who turned out to have no AR, the two methods agreed in $84.6 \%$ of patients; for patients who turned out to have AR grade 1, the two methods agreed in $73.7 \%$ of patients; for patients who turned out to have AR grade 2, the two methods agreed in 


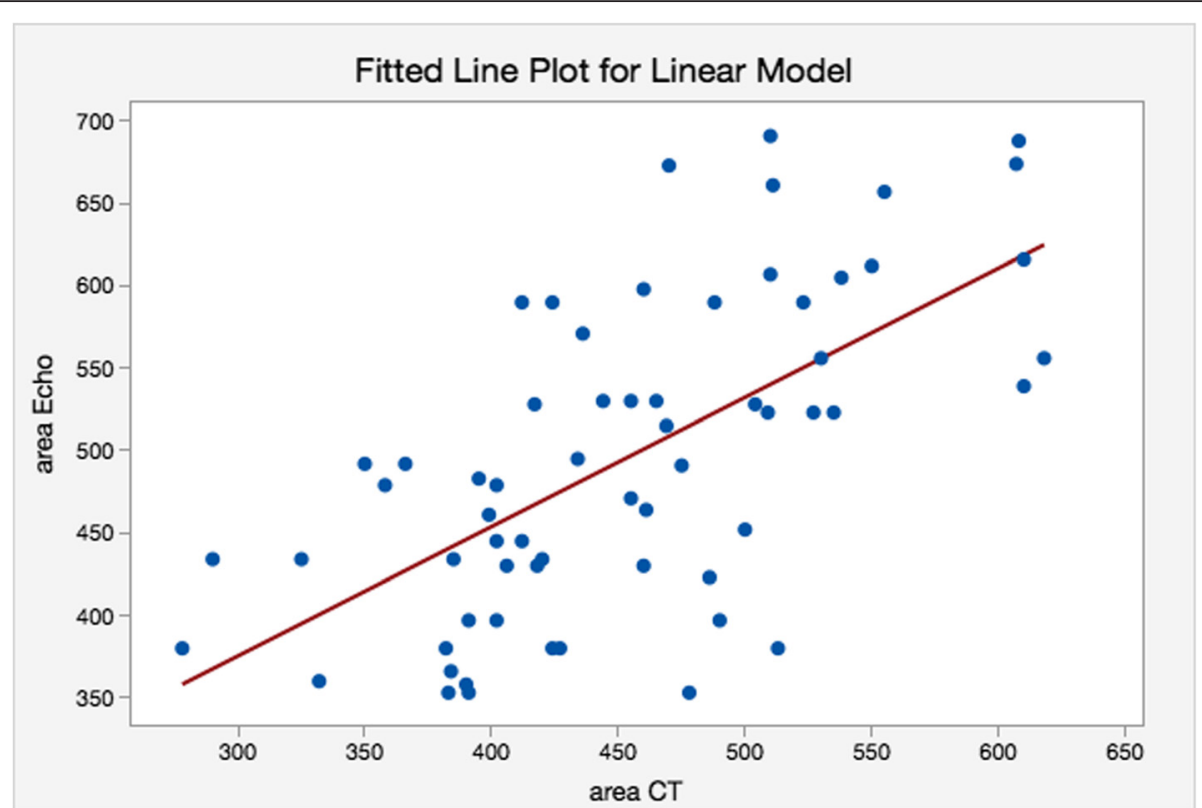

Fig. 4 A scatter plot of TEE derived area against CT derived area. The equation of the regression line is: area Echo $=140+0.785$ area/CT

$60.0 \%$ of patients. So it could be argued that the TEE derived area method disagreed with the CT method more often when the sizing using CT turned out to be unsatisfactory (Fig. 8).

However, this conclusion is based on very low frequencies and so is almost certainly not statistically significant.

\section{Discussion}

We analyzed the influence of different measurement techniques on the theoretical valve size selection in our patient population. Valve choice based on the TEE derived area demonstrated the best agreement to valve choice based on CT. The disagreement was more pronounced in the patients who had any degree of post-operative AR.

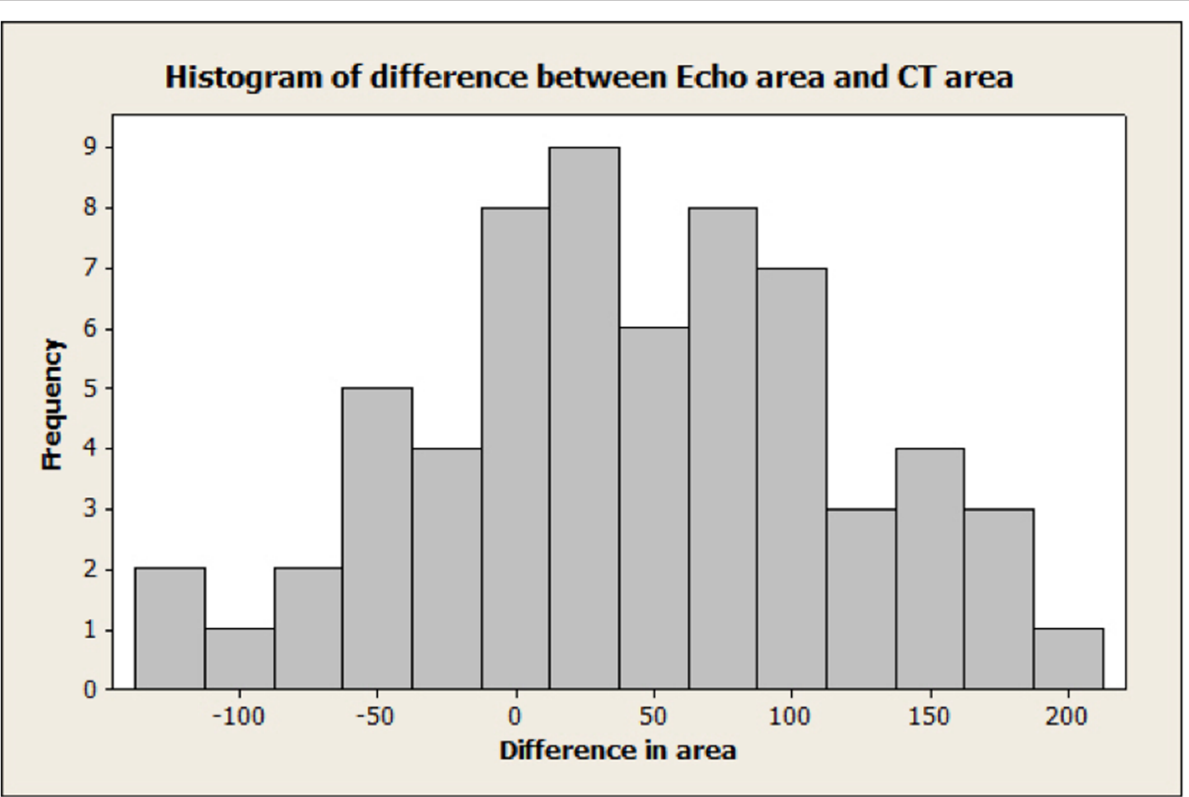

Fig. 5 A histogram of the difference: TEE derived area minus $C T$ derived area. There is a tendency for the echo areas to be higher $(p<0.001, t$-test) 


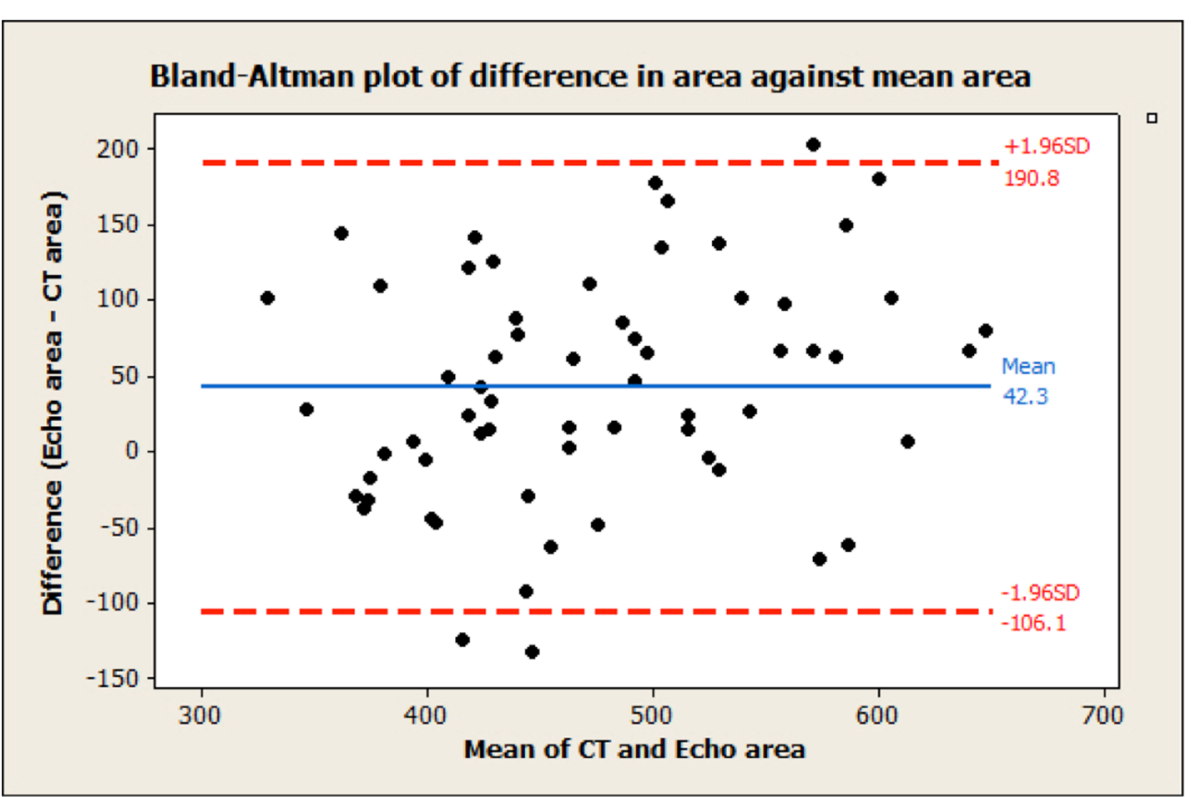

Fig. 6 The Bland-Altman plot of the difference (TEE derived area minus $C T$ derived area) against the mean area of TEE and CT. The red dotted lines show the range of differences between the measurements for most (about $95 \%$ ) of individuals

The indications for transcatheter prosthesis size selection provided by the manufacturers were based on 2D-TEE measurements [10]. This technique was used to accurately determine the size of the aortic annulus and the excellent results of TAVI reported to date may be attributable to these complementary techniques $[1,11-13]$.

The main limitation of echocardiography relates to its two-dimensional nature. The aortic root in fact has a complex three-dimensional geometry and the semi-lunar attachments of the aortic cusps take the shape of a 3pronged coronet. Working on a uni-planar view leads to the possibility of underestimating or overestimating the annular size, due to the fact that the actual plane of the section may lie out of the annulus center [14].

3-D TEE and a multi-planar reconstruction of the aortic root and of the outflow tract can overcome this limitation

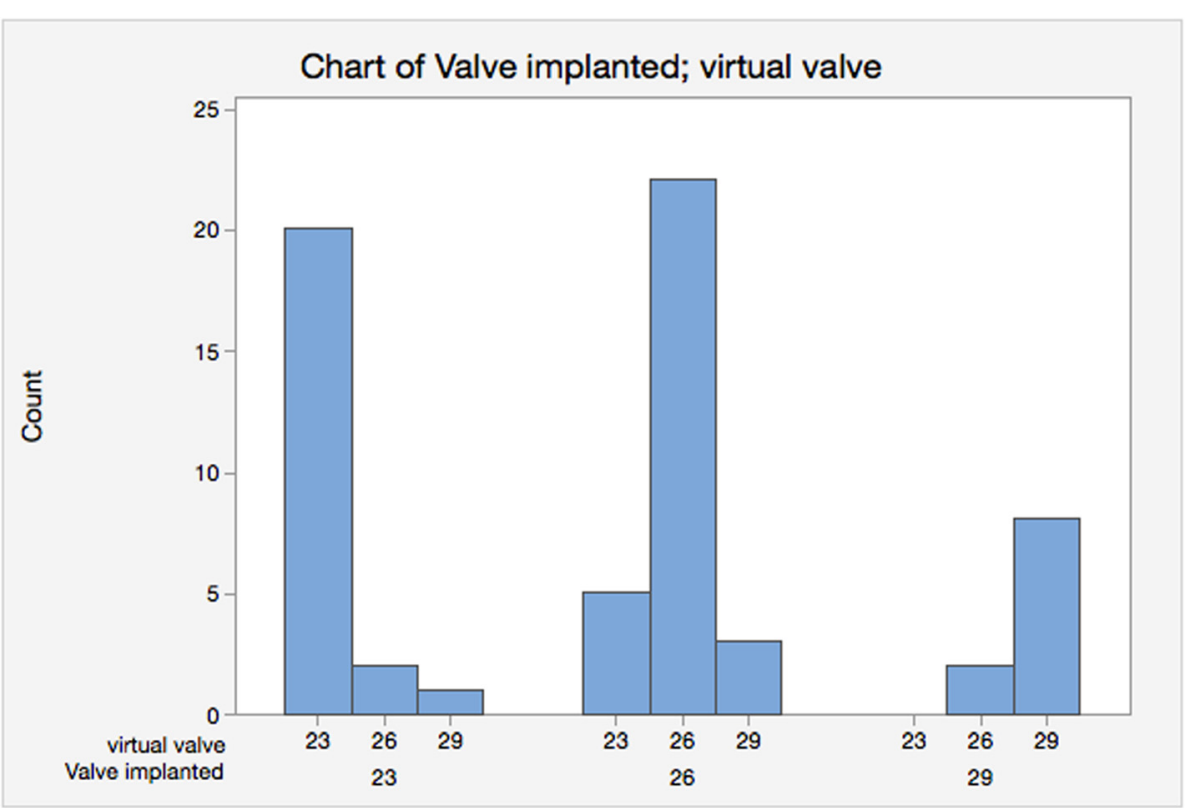

Fig. 7 Shows the frequencies of the virtual valve sizes according to TEE derived area in comparison to the real valve sizes 


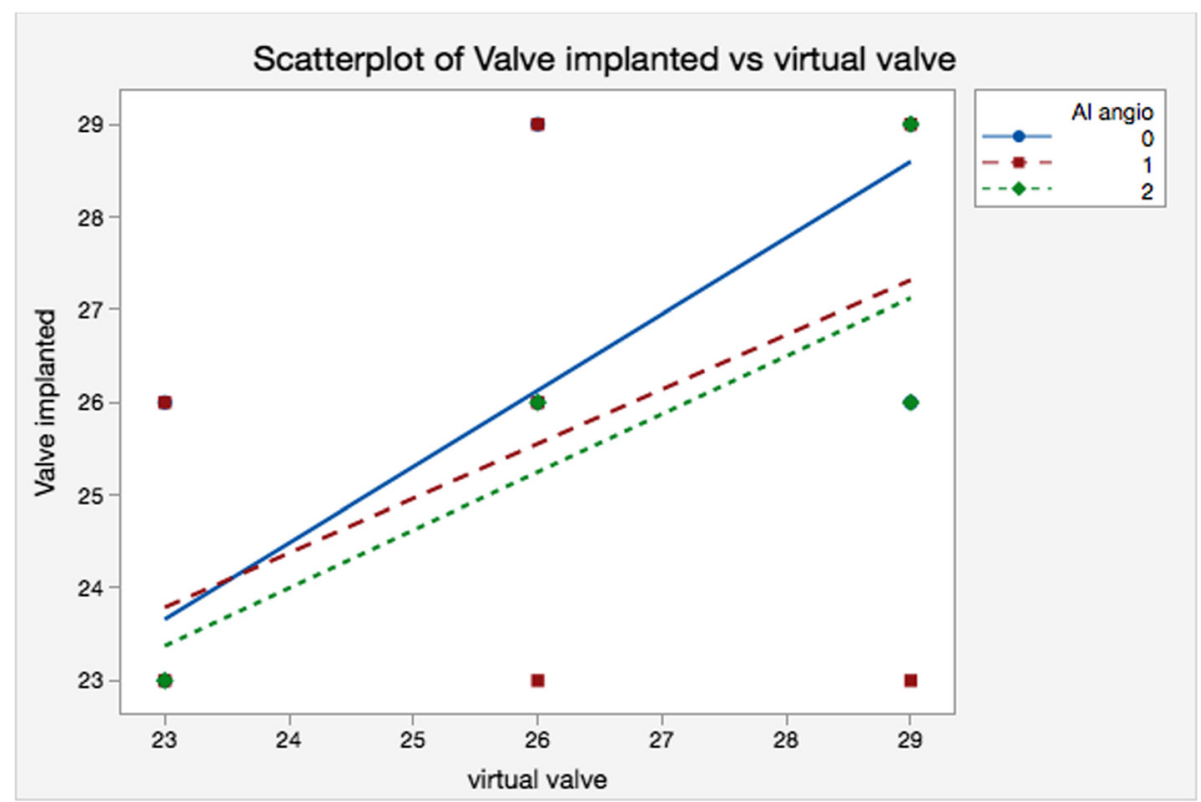

Fig. 8 Scatterplot of the implanted valve versus the virtual valve according to the degree of the AR

but the capacity to visualize the entire annulus can be limited by the calcifications [15].

An oversized prosthetic valve relative to the dimensions of the patient's aortic root can result in redundancy of leaflet tissue, thus creating folds. These folds will generate regions of compressive and tensile stresses and may alter the function or reduce the durability of the valve [16]. On the other hand, if the prosthesis is too small for the patient, the incidence of significant paravalvular regurgitation is high.

Anderson et al. [17] mentioned that, the essence of the anatomic arrangement of the aortic root is that the aortic valve leaflets are supported in crown-like fashion within the cylindrical root.

The diameter at the level of the basal attachment of the leaflets (green ring in Fig. 2) is the diameter that is usually defined as the valvular annulus. Nevertheless, it is no more than a virtual ring and does not correspond with the annulus defined by cardiac surgeons [17]. This level is the one used for sizing using CT.

In this study we used the top of the crown, which is a true anatomical ring, namely the sinutubular junction as a surrogate for the aortic valve annulus (blue ring in Fig. 2). It is thickened at the sites of peripheral attachment of the zones of apposition between the aortic valve leaflets (Red circles in Fig. 1).

In general, the diameter at the level of the sinutubular junction exceeds that at the level of the virtual basal ring by up to one-fifth [18]. This agrees with our findings, as we found that using the diameter for sizing was associated with a tendency to oversizing.
Moreover, the aortic root is a dynamic structure, with its geometric parameters changing continuously both during the phases of the cardiac cycle and in relation to changes in pressure within the aortic root [19]. From diastole to systole, the diameter at the level of the outlet has been noted to increase by $12 \%$, while the diameter at the base decreases by $16 \%$ [20].

CT has become the "gold standard" for measuring the aortic valve annulus as it allows a detailed understanding of the complex three-dimensional aortic root anatomy, including the crown-shaped anatomic aortic annulus, the virtual basal ring, and the sinuses of Valsalva with the origin of the coronary arteries.

Several studies $[5,21]$ have found that aortic annular sizing using $\mathrm{CT}$ in patients undergoing TAVI using the balloon expandable ES prosthesis is the most accurate method. Nevertheless, radiation exposure, iodine injection and costs are important limitations in comparison to using TEE. Moreover, over $50 \%$ of patients undergoing TAVI in large studies had pre-existing chronic kidney disease and about $10 \%$ of these patients have severe renal insufficiency [22, 23].

It should be observed, however, that the exact identification of the plane on which the basal ring lays is not always straightforward in clinical practice. In fact, the nadir of any particular cusp is located at the point where that cusp is "seen to disappear," and the operator judges that the plane is correctly oriented when the three cusps disappear all together, an occurrence that may be hard to reproduce in some patients, such as those with heavy or asymmetrical annular calcifications or an extremely elliptical annulus. 
While it is easy to identify the "height" of the nadir of a cusp in the aortic root on the sagittal and coronal oblique views, its angular position on the annular circumference may be hard to locate in some patients [15].

Several scan protocols for TAVI assessment have been developed. The technical details on how to obtain a good scan are beyond the scope of this article, but a high quality acquisition without artifacts is a pre-requisite for all the post-processing and image analysis [24].

It has recently been demonstrated that TAVI alters the geometry of the aortic annulus to a more circular configuration $[15,25]$. Therefore, we think that using the TEE derived area according to the circumcircle of a triangle method may accurately predicts the size of the valve as the area generated mimics the area of the bioprosthesis to be implanted.

Most importantly, the present study demonstrates that the TEE derived area may be a plausible method for measuring the aortic annulus and provide accurate information comparable to CT.

For borderline aortic annulus dimensions, ES size selection may be challenging. This TEE method may help the operator with an extra tool to validate, if not to correct, the measurements done using CT.

\section{Conclusions}

CT remanis the gold standard in sizing of the aortic valve annulus. Nevertheless, sizing of the aortic valve annulus using TEE derived area may give additional information. The impact of integration of this method in the algorithm of aortic annulus sizing on the outcome of patients undergoing TAVI should be examined in future studies.

\section{Limitations}

This study is a non-randomized study having its inherent limitations. A randomized non-inferiority or better superiority study comparing both methods and their impact on the outcome regarding the incidence of postoperative AR, aortic annulus rupture and valve embolization is warranted. The small number of patients is a limitation in this study, but it is the first step to validate this novel method. All patients received an ES balloon-expandable prosthesis. Therefore, findings of this study may not apply to the selfexpandable prosthesis.

\begin{abstract}
Abbreviations
AR: Aortic regurgitation; AV: Aortic valve; AVA: Aortic valve area; CT: Multidetector computed tomography; ES: Edwards-Sapien; LVOT: Left ventricular outflow tract; LCC: Left coronary cusp; MPR: Multiplanar reformation; NCC: Non-coronary cusp; RCC: Right coronary cusp; TAVI: Transcatheter aortic valve implantation; TTE: Transthoracic echocardiography; 2D-TEE: Two-dimensional transesophageal echocardiography; 3D-TEE: Three-dimensional transesophageal echocardiography.
\end{abstract}

\section{Competing interests}

The authors declare that they have no competing interests.

\section{Authors' contributions}

MS and WV carried out the procedures; MS and AÖ drafted the manuscript. TR, GE, OM participated in the design of the study. $\mathrm{HI}$ had and participated the study design helped to draft the manuscript. All authors read and approved the final manuscript.

\section{Acknowledgements}

This research received no grant from any funding agency in the public, commercial or not-for-profit sectors.

\section{Author details}

${ }^{1}$ Internal Medicine Centre, Cardiology Department, Rostock University Clinic, Ernst-Hyedemann- Street 6, 18057 Rostock, Germany. ${ }^{2}$ I. Internal Medicine Clinic, Cardiology Department, Wuerzburg University Clinic, Wuerzburg, Germany.

Received: 14 October 2015 Accepted: 21 December 2015

Published online: 29 December 2015

\section{References}

1. Tuzcu EM, Kapadia SR, Schoenhagen P. Multimodality quantitative imaging of aortic root for transcatheter aortic valve implantation: more complex than it appears. J Am Coll Cardiol. 2010;55(3):195-7. doi:10.1016/j.jacc.2009.07.063.

2. Jilaihawi H, Kashif M, Fontana G, Furugen A, Shiota T, Friede G, et al. Crosssectional computed tomographic assessment improves accuracy of aortic annular sizing for transcatheter aortic valve replacement and reduces the incidence of paravalvular aortic regurgitation. J Am Coll Cardiol. 2012;59(14): 1275-86. doi:10.1016/j.jacc.2011.11.045.

3. Jilaihawi H, Doctor N, Kashif M, Chakravarty T, Rafique A, Makar M, et al. Aortic annular sizing for transcatheter aortic valve replacement using crosssectional 3-dimensional transesophageal echocardiography. J Am Coll Cardiol. 2013;61(9):908-16. doi:10.1016/j.jacc.2012.11.055.

4. Binder RK, Webb JG, Willson AB, Urena M, Hansson NC, Norgaard BL, et al. The impact of integration of a multidetector computed tomography annulus area sizing algorithm on outcomes of transcatheter aortic valve replacement: a prospective, multicenter, controlled trial. J Am Coll Cardiol. 2013;62(5):431-8. doi:10.1016/j.jacc.2013.04.036.

5. Willson AB, Webb JG, Labounty TM, Achenbach S, Moss R, Wheeler M, et al. 3-dimensional aortic annular assessment by multidetector computed tomography predicts moderate or severe paravalvular regurgitation after transcatheter aortic valve replacement: a multicenter retrospective analysis. J Am Coll Cardiol. 2012;59(14):1287-94. doi:10.1016/j.jacc.2011.12.015.

6. Willson AB, Webb JG, Freeman M, Wood DA, Gurvitch R, Thompson CR, et al. Computed tomography-based sizing recommendations for transcatheter aortic valve replacement with balloon-expandable valves: comparison with transesophageal echocardiography and rationale for implementation in a prospective trial. J Cardiovasc Comput Tomogr. 2012;6(6):406-14. doi:10. 1016/j.jcct.2012.10.002.

7. Achenbach S, Delgado V, Hausleiter J, Schoenhagen P, Min JK, Leipsic JA. SCCT expert consensus document on computed tomography imaging before transcatheter aortic valve implantation (TAVI)/transcatheter aortic valve replacement (TAVR). J Cardiovasc Comput Tomogr. 2012;6(6):366-80. doi:10.1016/j.jcct.2012.11.002.

8. Leon MB, Piazza N, Nikolsky E, Blackstone EH, Cutlip DE, Kappetein AP, et al. Standardized endpoint definitions for transcatheter aortic valve implantation clinical trials: a consensus report from the Valve Academic Research Consortium. Eur Heart J. 2011;32(2):205-17. doi:10.1093/eurheartj/ehq406.

9. Authors/Task Force M, Vahanian A, Alfieri O, Andreotti F, Antunes MJ, BaronEsquivias $\mathrm{G}$, et al. Guidelines on the management of valvular heart disease (version 2012): The Joint Task Force on the Management of Valvular Heart Disease of the European Society of Cardiology (ESC) and the European Association for Cardio-Thoracic Surgery (EACTS). Eur J Cardiothorac Surg. 2012;42(4):S1-44. doi:10.1093/ejcts/ezs455.

10. Vahanian A, Alfieri O, Al-Attar N, Antunes M, Bax J, Cormier B, et al. Transcatheter valve implantation for patients with aortic stenosis: a position statement from the European association of cardio-thoracic surgery (EACTS) and the European Society of Cardiology (ESC), in collaboration with the European Association of Percutaneous Cardiovascular Interventions (EAPCI). Eurolntervention. 2008;4(2):193-9.

11. Dashkevich A, Blanke P, Siepe M, Pache G, Langer M, Schlensak C, et al. Preoperative assessment of aortic annulus dimensions: comparison of 
noninvasive and intraoperative measurement. Ann Thorac Surg. 2011;91(3): 709-14. doi:10.1016/j.athoracsur.2010.09.038.

12. Kempfert J, Van Linden A, Lehmkuhl L, Rastan AJ, Holzhey D, Blumenstein J, et al. Aortic annulus sizing: echocardiographic versus computed tomography derived measurements in comparison with direct surgical sizing. Eur J Cardiothorac Surg. 2012;42(4):627-33. doi:10.1093/ejcts/ezs064.

13. Messika-Zeitoun D, Serfaty JM, Brochet E, Ducrocq G, Lepage L, Detaint D, et al. Multimodal assessment of the aortic annulus diameter: implications for transcatheter aortic valve implantation. J Am Coll Cardiol. 2010;55(3): 186-94. doi:10.1016/j.jacc.2009.06.063.

14. Piazza N, de Jaegere P, Schultz C, Becker AE, Serruys PW, Anderson RH. Anatomy of the aortic valvar complex and its implications for transcatheter implantation of the aortic valve. Circ Cardiovasc Interv. 2008;1(1):74-81. doi:10.1161/CIRCINTERVENTIONS.108.780858.

15. Cerillo AG, Mariani M, Berti S, Glauber M. Sizing the aortic annulus. Ann Cardiothorac Surg. 2012;1(2):245-56. doi:10.3978/j.issn.2225-319X.2012.06.13.

16. Thubrikar M, Piepgrass WC, Shaner TW, Nolan SP. The design of the normal aortic valve. Am J Physiol. 1981;241 (6):H795-801.

17. Anderson RH. Clinical anatomy of the aortic root. Heart. 2000;84(6):670-3.

18. Piazza N, Onuma Y, Jesserun E, Kint PP, Maugenest AM, Anderson RH, et al. Early and persistent intraventricular conduction abnormalities and requirements for pacemaking after percutaneous replacement of the aortic valve. JACC Cardiovasc Interv. 2008;1(3):310-6. doi:10.1016/j.jcin.2008.04.007.

19. Swanson M, Clark RE. Dimensions and geometric relationships of the human aortic valve as a function of pressure. Circ Res. 1974;35(6):871-82.

20. Brewer RJ, Deck JD, Capati B, Nolan SP. The dynamic aortic root. Its role in aortic valve function. J Thorac Cardiovasc Surg. 1976;72(3):413-7.

21. Wuest W, Anders K, Schuhbaeck A, May MS, Gauss S, Marwan M, et al. Dual source multidetector $C T$-angiography before Transcatheter Aortic Valve Implantation (TAVI) using a high-pitch spiral acquisition mode. Eur Radiol. 2012;22(1):51-8. doi:10.1007/s00330-011-2233-0.

22. Rodes-Cabau J, Webb JG, Cheung A, Ye J, Dumont E, Feindel CM, et al. Transcatheter aortic valve implantation for the treatment of severe symptomatic aortic stenosis in patients at very high or prohibitive surgical risk: acute and late outcomes of the multicenter Canadian experience. J Am Coll Cardiol. 2010;55(11):1080-90. doi:10.1016/j.jacc.2009.12.014.

23. Dumonteil $\mathrm{N}$, van der Boon RM, Tchetche D, Chieffo A, Van Mieghem NM, Marcheix B, et al. Impact of preoperative chronic kidney disease on short- and long-term outcomes after transcatheter aortic valve implantation: a PooledRotterdAm-Milano-Toulouse In Collaboration Plus (PRAGMATIC-Plus) initiative substudy. Am Heart J. 2013;165(5):752-60. doi:10.1016/i.ahj.2012.12.013.

24. Leipsic J, Gunvitch R, Labounty TM, Min JK, Wood D, Johnson M, et al. Multidetector computed tomography in transcatheter aortic valve implantation. JACC Cardiovasc Imaging. 2011:4(4):416-29. doi:10.1016/j.jcmg.2011.01.014.

25. Blanke P, Siepe M, Reinohl J, Zehender M, Beyersdorf F, Schlensak C, et al. Assessment of aortic annulus dimensions for Edwards SAPIEN Transapical Heart Valve implantation by computed tomography: calculating average diameter using a virtual ring method. Eur J Cardiothorac Surg. 2010;38(6): 750-8. doi:10.1016/j.ejcts.2010.03.039.

\section{Submit your next manuscript to BioMed Central and we will help you at every step:}

- We accept pre-submission inquiries

- Our selector tool helps you to find the most relevant journal

- We provide round the clock customer support

- Convenient online submission

- Thorough peer review

- Inclusion in PubMed and all major indexing services

- Maximum visibility for your research

Submit your manuscript at www.biomedcentral.com/submit

C Biomed Central 